\title{
Rarity of mineral fibre pleurisy among persons exposed to Finnish anthophyllite and with low risk of mesothelioma
}

\author{
GUNNAR HILLERDAL, ANDERS ZITTING, ALEXANDER HW van ASSENDELFT, \\ TIMO KUUSELA
}

From the Department of Pulmonary Medicine, University Hospital, Uppsala, Sweden; the Department of Radiology, Institute of Occupational Health, Helsinki, Finland; and the Department of Pulmonary Diseases, North Karelian Central Hospital, Kontioniemi Hospital, Kontioniemi, Finland

ABSTRACT Endemic pleural plaques are reported from many parts of the world. In Central Europe and in Finland no connection with malignant mesotheliomas has been found, whereas this tumour is often encountered in areas in Turkey where endemic plaques also occur. There seem, however, to be differences in the radiological appearances found in these areas. In the present study chest radiographs of 317 persons with pleural plaques from the endemic area of Finland were scrutinised. It was found that $4.7 \%$ showed a blunted costophrenic angle unilaterally and $0.9 \%$ bilaterally. The prevalence of sequelae of pleurisy is statistically very highly significantly lower than in people with pleural plaques in Turkey. As the risk of mesothelioma appears to be low in Finland, the results are in accordance with the hypothesis that the risk of mesothelioma in a given population is higher if in that population there is a high incidence of benign asbestos pleurisy.

The endemic occurrence of pleural plaques was first described from Finland' ${ }^{1}$ and has since been reported from many parts of the world. ${ }^{2}$ Various mineral fibres in the ground have been identified as the probable cause. Interestingly, Finnish and Central European endemic plaques seem to have no connection with the occurrence of malignant pleural mesothelioma, ${ }^{3}$ whereas those in Turkey are associated with a sometimes very high risk of development of this otherwise rare tumour. ${ }^{4}$ A study in Turkey indicated that among populations with a high risk of mesothelioma there was a high incidence of sequelae of pleurisy, presumed to be related to asbestos. ${ }^{5}$ Comprehensive reports of the frequency of mesothelioma among persons with nonoccupational pleural plaques in Finland are still lacking but available data indicate that the prevalence is lower than in the mineral fibre areas of Turkey, and

Address for reprint requests: Dr G Hillerdal, University of Uppsala Department of Lung Medicine, University Hospital, S750 14 Uppsala, Sweden.

Accepted 4 April 1984 certainly lower than in the erionite areas. In a follow up examination of 608 people with pleural calcification detected in mass radiography in 1972 in selected communities in Finland no pleural mesothelioma was registered until the end of 1976 ( $\mathrm{T}$ Partanen, personal communication).

If there is a correlation between mesothelioma risk and the incidence of benign asbestos pleurisy then the frequency of sequelae of pleurisy should be low among those with plaques in Finland. The aim of this study was to test this hypothesis.

\section{Methods}

ASBESTOS DEPOSITS AND MINING IN FINLAND

Asbestos in the form of anthophyllite can be found scattered in Eastern Finland. The largest deposits occur in North Karelia, particularly in the communes of Tuusniemi and Outokumpu (formerly Kuusjärvi) (fig 1). The mineral occurs in large lenses. Mining first began some $\mathbf{4 0 0 0}$ years ago and continued for more than 2000 years, asbestos being exported to northern Scandinavia and other nearby areas for use as a strengthener in ceramics. ${ }^{2}$ In 


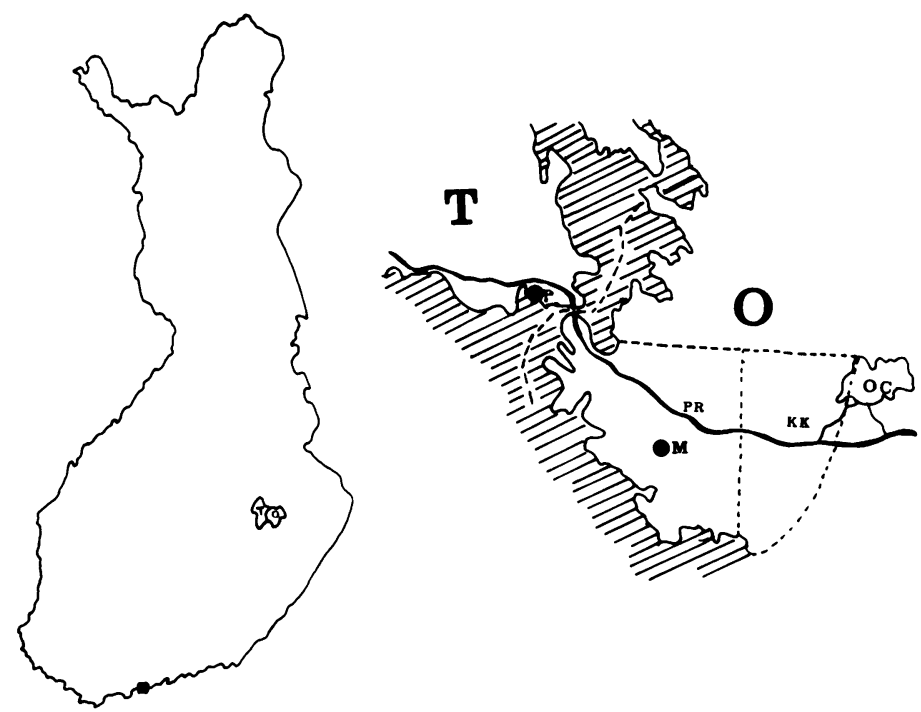

Fig 1 (a) Map of Finland, showing the asbestos area (arrow). (b) The asbestos area, with the main roads marked. T-Tuusniemi commune; O-Outokumpu (formerly Kuusjärvi) commune; OC-town of Outokumpu (Black circles are

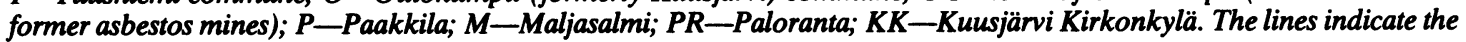
area where the population was surveyed. Shaded areas are lake.

more recent times two mines have been actively exploited. The larger one, Paakkila in the Tuusniemi commune, started operations in 1918 and closed down in 1975 because of the dust problem. ${ }^{3}$ A smaller mine, Maljasalmi in the commune of Outokumpu, was mined from 1944 to 1952. The anthophyllite was used in asbestos cement and for insulation, roofing material, and so on. The mining took place in large open air pits and the asbestos was then transported along the main roads in open trucks. The conditions were very dusty, and mineral fibres could be found widely spread from the mine. ${ }^{6}$

\section{MATERIAL}

Health surveys with miniature chest radiography have been carried out in Finland since the end of the second world war. Nowadays only selected high risk groups are surveyed, since the yield from the general surveys has become progressively lower. The films from the last local general survey in 1974 in the two small westernmost areas of the Outokumpu Commune, Paloranta with the asbestos mine Maljasalmi and Kuusjärvi Kirkonkylä nearby, were reexamined. The commune of Rääkkylä about $60 \mathrm{~km}$ south east from Outokumpu was used as a control area.

North Karelia is sparsely populated and the people gain their living mainly from agriculture and forestry, though there are also some metal mines and small industries. The country is very beautiful and unspoilt, with an abundance of lakes and for- ests, but shortage of employment for the young has led to emigration towards the Finnish coast and to the cities, especially in the 1960 s and early 1970 s. Those who live in North Karelia have usually done so from birth.

\section{METHODS}

The chest radiographs were scrutinised for pleural plaques, both calcified and non-calcified, and for sequelae of pleurisy (blunting of any costophrenic angle). Special note was taken of visibility or any widening of the minor fissure. In most cases only posteroanterior projections were available and lateral views were therefore disregarded. The term pleural plaques is used to indicate typical bilateral calcified or uncalcified plaques and typical unilateral calcified plaques. Unilateral hyaline plaques alone were not classified as pleural plaques for the purpose of this study. The sex and age of the subjects were noted. The $\chi^{2}$ test was used in statistical tests.

Table 1 Pleural plaques in various areas

\begin{tabular}{lcc}
\hline Area & $\begin{array}{l}\text { No of } \\
\text { radiographs }\end{array}$ & $\begin{array}{l}\text { No (\%) with pleural } \\
\text { plaques }\end{array}$ \\
\hline Kuusjärvi & 587 & $137(23 \cdot 3)$ \\
Kirkonkylä & 503 & $180(35 \cdot 8)$ \\
$\begin{array}{l}\text { Paloranta } \\
\text { Total from "asbestos areas" } 1090\end{array}$ & $317(29 \cdot 1)$ \\
No of controls & 1073 & $4(0 \cdot 4)$ \\
\hline
\end{tabular}




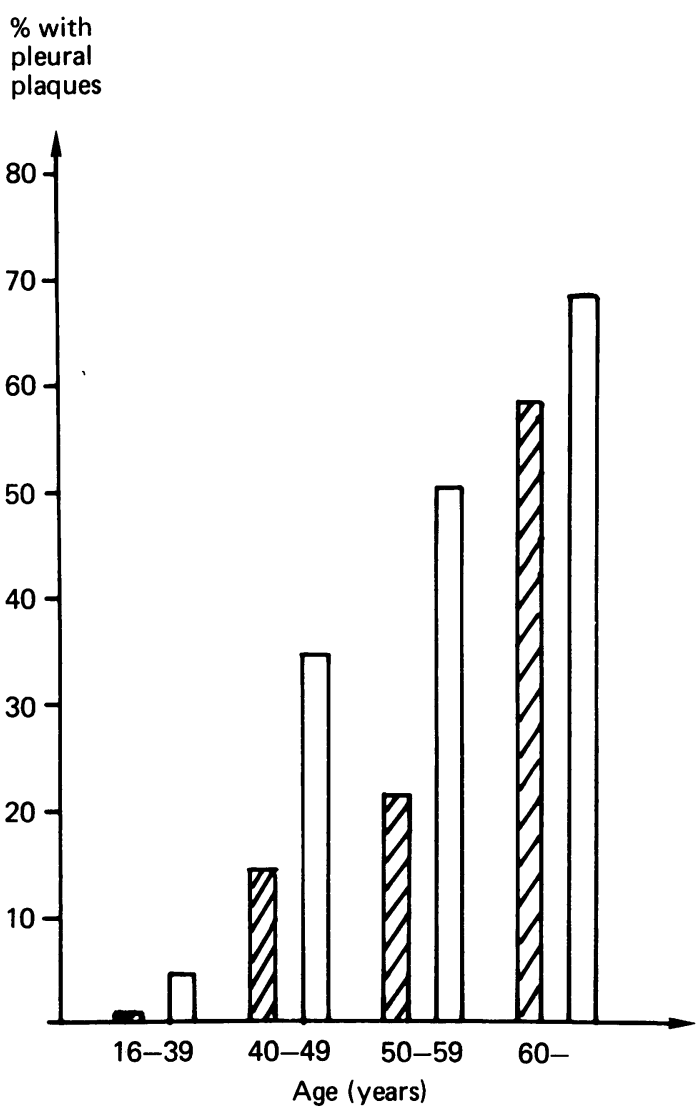

Fig 2 Percentage of population in the asbestos areas with pleural plaques according to age. The hatched columns represent Kirkonkylä and the plain columns Paloranta.

\section{Results}

There were 1090 chest radiographs from Paloranta and Kuusjärvi Kirkonkylä and 1073 controls (table 1). The sex and age distributions were the same. In the asbestos areas 317 subjects, or 29.1 per cent, were found to have pleural plaques, while this finding occurred in only 4 of the control subjects (less than 0.4 per cent).
Pleural plaques The incidence of plaques increased rapidly with age (fig 2 ). There was no significant sex difference: in Kuusjärvi Kirkonkylä the incidence of pleural plaques was $23.5 \%$ among men and $23.1 \%$ among women, while in Paloranta the corresponding figures were $37.6 \%$ and $33.9 \%$. The vast majority of the pleural plaques were bilateral and calcified ( 260 of the 317 subjects $-82 \%$ ); 33 subjects $(10.4 \%)$ had unilateral calcified plaques and 24 $(7.5 \%)$ had bilateral hyaline plaques.

Blunted costophrenic angle and visibility of minor fissure The only difference between the subjects from asbestos areas and the controls with respect to blunted costophrenic angles and the visibility of minor fissures was a difference of low grade significance in the prevalence of bilaterally blunted costophrenic angles (table 2). This, however, was due to an excess among subjects without plaques.

\section{Discussion}

Kiviluoto ${ }^{1}$ was the first to publish a scientific description of the plaques in Eastern Finland. According to him, in 1959 the incidence of calcified plaques in those above the age of 15 years in the commune of Kuusjärvi (now Outokumpu) was $7.9 \%$. Raunio ${ }^{6}$ gave a figure of $6.4 \%$ in 1966 , while the incidence in other Finnish rural communities was $0.054 \% .^{6}$ The figures for Kuusjärvi (Outokumpu) were for the whole commune and therefore not comparable to the selected part described here.

Both Finnish authors attribute the plaques to spread of asbestos fibres from the mines. Measurable amounts were found up to $27 \mathrm{~km}$ from the Paakkila mine. ${ }^{6}$ Transportation in open trucks would cause widespread pollution in dry weather conditions. It seems unlikely, however, that this kind of pollution could lead to such an extensive occurrence of pleural calcification among the general population. Other suggested explanations have been the local use of asbestos rocks in sauna baths and ovens, while children may play with discarded and scattered rocks. ${ }^{167}$

Another possibility is pollution of the water with

Table 2 Number (and percentage) of radiographs with blunted costophrenic angle and visibility of minor fissure

\begin{tabular}{|c|c|c|c|c|c|}
\hline \multirow[t]{2}{*}{ Area } & \multirow[t]{2}{*}{ Total No } & \multicolumn{2}{|c|}{ Blunted costophrenic angles } & \multirow[t]{2}{*}{ Visible minor fissure } & \multirow[t]{2}{*}{ Calcified } \\
\hline & & Unilateral & Bilateral & & \\
\hline $\begin{array}{l}\text { Asbestos areas } \\
\text { Persons without plaques } \\
\text { Persons with plaques } \\
\text { Total } \\
\text { Controls } \\
\text { Significance (p) of difference } \\
\text { between cases and controls }\end{array}$ & $\begin{array}{l}773(70.9) \\
317(29 \cdot 1) \\
1090 \\
1073\end{array}$ & $\begin{array}{l}60(7 \cdot 8) \\
15(4 \cdot 7) \\
75(6 \cdot 9) \\
60(6 \cdot 5) \\
N S\end{array}$ & $\begin{array}{r}17(2 \cdot 2) \\
3(0.9) \\
20(1.8) \\
8(0.7) \\
<0.05\end{array}$ & $\begin{aligned} & 97(2 \cdot 5) \\
& 25(7 \cdot 9) \\
& 12211 \cdot 1) \\
& 97(9 \cdot 0)\end{aligned}$ & $\begin{array}{l}3(0.9) \\
3(0.3)\end{array}$ \\
\hline
\end{tabular}


asbestos fibre, which seems quite plausible in view of the geology of the area. Washing and cleaning could lead to air pollution by fibres once the water has evaporated. This possibility is worth further investigation.

No mesotheliomas have been reported among people with endemic plaques in Finland, while this tumour is relatively common in those from South Africa and Turkey who have such changes. Sequelae of pleurisy are more common in Turkish villages where there is a high risk of mesothelioma. ${ }^{5} \mathrm{~A}$ blunted costophrenic angle was seen unilaterally in $23.2 \%$ of people with bilateral pleural calcification in Turkish erionite villages (where the risk of mesothelioma is very high) and bilaterally in $9 \%$. These figures are very significantly $(\mathrm{p}<0.001)$ higher than in our series of subjects $(4.7 \%$ and $0.9 \%$ respectively) with anthophyllite plaques.

Thus the radiological features encountered in populations exposed to different mineral fibres are not the same. All too often asbestos related changes are lumped together as "pleural changes," which leads to loss of valuable information. The ILO/ UICC classification should once again be revised to make clear the distinctions between various pleural changes.

In the erionite villages almost all inhabitants complain of sudden thoracic pains (YI Baris, 1981, personal communication). We questioned some former workers-one of whom had severe asbestosisconcerning such symptoms among the miners, but they denied that they occurred. Nor had any workers ever had so called asbestos warts. Such symptoms (or the lack of them) might provide further clues to the biological effects of various fibres.
We wish to emphasise that the relationship with benign mineral fibre pleurisy does not apply to bronchial carcinomas. This tumour seems to occur in connection with all types of asbestos exposure and the influence of smoking makes evaluation difficult. Much more data need to be assembled before any conclusions regarding mineral fibre pleurisies and bronchial carcinoma can be drawn.

We want to thank the staff of the Joensuu Central Dispensary for their invaluable aid.

\section{References}

' Kiviluoto R. Pleural calcification as a roentgenologic sign of non-occupational endemic anthophylliteasbestosis. Acta Radiol 1960; suppl 194:1-65.

${ }^{2}$ Hillerdal G. Pleural plaques-occurrence, exposure to asbestos, and clinical importance. Acta Universitatis Upsaliensis 1980;363:1-227.

${ }^{3}$ Huuskonen MS. Asbestosis in Finland. Clinical and immunological findings and mortality among asbestosis patients. Academic dissertation, University of Helsinki, 1979.

${ }^{4}$ Baris Y, Artvinli M, Sahin AA. Environmental mesothelioma in Turkey. Ann N Y Acad Sci 1979;330:423-32.

${ }^{5}$ Hillerdal G, Baris YI. Radiological study of pleural changes in relation to mesothelioma in Turkey. Thorax 1983;38:443-8.

${ }^{6}$ Raunio V. Occurrence of unusual pleural calcification in Finland. Studies on atmospheric pollution caused by asbestos. Ann Med Intern Fenniae 1966;55, suppl 4T:1-61.

${ }^{7}$ Meurman LO. Pleural fibrocalcific plaques and asbestos exposure. Environ Res 1968;2:30-46. 